\title{
The energy-environmental efficiency of the existing building stock through morphological-constructive solutions: the case study of a single- family building in Sicily.
}

\author{
F. Blundo, F. Foti, F. Leone, F. Nocera, L. Savoca \\ Department of Civil Engineering and Architecture \\ DICAR, University of Catania \\ Viale Andrea Doria 6, 95100 Catania (Italy) \\ Phone/Fax number:+0039392 2275652, e-mail: federica.leone@phd.unict.it, fabioblundo@hotmail.it, \\ savocaluca@gmail.com, fnocera@unict.it, fabfoti@tin.it
}

\begin{abstract}
The protection of environmental resources, both energy and natural, is a current and urgent necessity for contemporary society. Since the building sector is responsible for a large part of energy and environmental consumption, the possibilities for savings in this sector are vast, starting with improving the quality of buildings. Therefore, the ecological orientation of the construction sector today represents a valid and necessary response to the sustainable development requirement to reduce the pressure on the environment in terms of impacts and consumption of resources. This is especially true if applied to the recovery and energy-environmental efficiency of the existing building stock. The aim of this study is to propose a methodology of "good practices" for the rehabilitation of nonhistoric buildings in terms of formal, functional, comfort and environmental quality, a methodology that combines the theme of architectural quality with that of environmental sustainability. In particular, the aim is to demonstrate how morphologicalconstructive solutions can be a valid response to the requirements of energy performance, environmental sustainability and occupant wellbeing. To this end, a case study of the renovation of a single-family building from the 1970s in the municipality of Ispica is reported, in which the proposed methodology is applied.
\end{abstract}

Key words. Environment, Architecture, Comfort, Energy, Sustainability.

\section{Introduction}

The environmental issue of pollution and climate change must now be the focus of discussion on the future of the building sector. Actually, it has a significant impact on the use of non-renewable resources, land use, energy consumption and emissions of climate-changing gases [1]. The building sector is therefore obliged to turn its gaze towards a conscious and responsible architecture that aims at the comfort and quality of the environment, as well as limiting the consumption of natural resources and the impact on the environment during the entire life cycle of the building. This change must and cannot only involve new buildings, but also the existing building stock - which often does not pay much attention to issues of environmental eco-efficiency - which in developed OECD countries represents the dominant share of the market. In Italy, for example, of the total number of buildings surveyed in 2011 (12.2 million), residential buildings account for $84.3 \%, 61 \%$ of which were built between 1946 and 1990 (ISTAT, 2011) (Fig. 1). In this operation of transition to "sustainable" architecture, it is important that the project is conceived in a conscious manner, keeping the architectural aspect as the pivotal point of the design. It is necessary to overcome, therefore, the idea that it is sufficient to install innovative, highly energy-efficient plant engineering systems. It is necessary to conceive of the work as a whole, integrating contemporary languages and technical-construction methods, the different design approaches of bioclimatic, green building and ecological architecture, verifying each time their effects (comfort, well-being, reduction of consumption) and their environmental consequences (consumption of energy and resources).

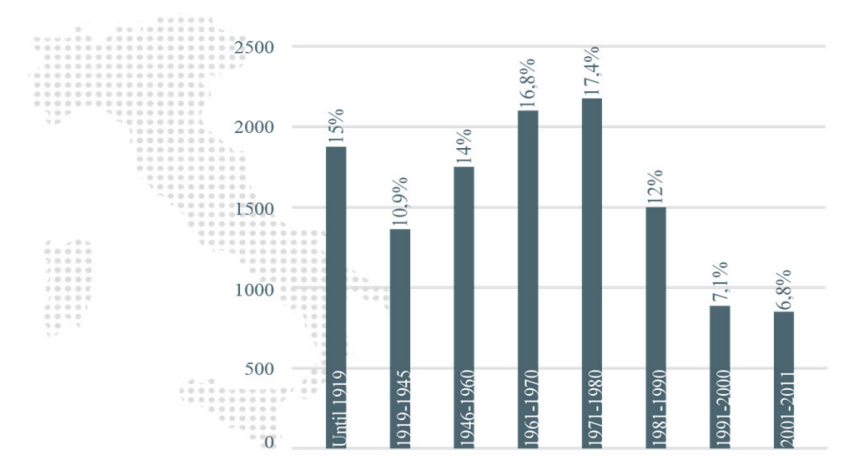

Fig. 1. Residential buildings in Italy by year of construction

\section{Methodology}

The aim of the article is to propose a methodology for the redevelopment of non-historic buildings that combines the theme of quality and architectural identity with that of environmental sustainability, the performance characteristics of the building with its formal, material and spatial conception. In this regard, the aim is to demonstrate how the conception - by means of design - of a complex architectural organism can already passively satisfy comfort and energy efficiency requirements, thanks to 
suitable physiognomic characteristics. In order to achieve this objective, the following steps will be carried out:

- $\quad$ in a preliminary phase, a cognitive analysis of both the building context and the environmental context will be carried out; in this sense, it is fundamental to assess all those microclimatic, biophysical and anthropic factors that influence the thermo-physical performance and usability of the building under study;

- $\quad$ subsequently, it is necessary to analyse and assess the morphological-typological and technical-constructive characteristics of the building in order to evaluate its thermo-hygrometric behaviour;

- $\quad$ the thermo-hygrometric behaviour of the building will be investigated by means energy simulations in dynamic regime for the evaluation of the thermohygrometric comfort of the occupants and the summer and winter energy requirements;

- the results obtained will be interpreted in terms of critical points to be resolved and potentialities to be exploited in order to define effective strategies for the requalification;

- $\quad$ finally, the total reconfiguration of the building will be carried out by applying the intervention strategies considered optimal both at a formal and constructive level and the effectiveness of the interventions will be verified by means of the dynamic energy analysis.

The environmental validity of the intervention will be investigated through an analysis of a Life Cycle Assessment (LCA) [2],[3], estimating the environmental benefits deriving from the transformation of the building against those of demolishing and rebuilding it. Particular attention will be paid to those design solutions aimed at giving the building a stereometric and essential character, in accordance with the building tradition of the geographical, cultural and environmental context.

\section{Case Study}

The case study is a single-family residential building from the 1970s located in the municipality of Ispica (latitude $36^{\circ} 47^{\prime} 7^{\prime \prime} 80 \mathrm{~N}$ - longitude $14^{\circ} 54^{\prime} 25^{\prime \prime} 56 \mathrm{E}$ ) in the province of Ragusa in the south-eastern part of Sicily. The building is located in the north-west of the municipality in a predominantly residential area characterised by small apartment blocks and detached houses.

\section{A. Morphological and constructional features}

The building, which has a north-east/south-west orientation, has three floors above ground and is characterised by a useful surface area of $231 \mathrm{~m}^{2}$ and a volume of $1400 \mathrm{~m}^{3}$. The elevations are characterised by a system of openings consisting of windows and French doors of regular shape and small size. The openings in the stairwell, on the other hand, are distinguished by their shape and arrangement and make the latter highly recognisable. In general, the volumetric composition of the building consists of an assemblage of volumes which are developed on several levels, giving a heterogeneous and irregular form to the exterior (Fig. 2). From a construction point of view, the building is characterised by different vertical opaque closures: those on the ground floor are made of hollow concrete blocks, those on the first and second floors and in the stairwell are made of a double row of perforated bricks with an air gap. With reference to the horizontal opaque closures, the floor against the ground has a reinforced concrete slab on a stone crawl space. The other floors are made of brick. As for the transparent closure, the windows and doors had a wooden frame with single glazing and screening systems with wooden shutters.

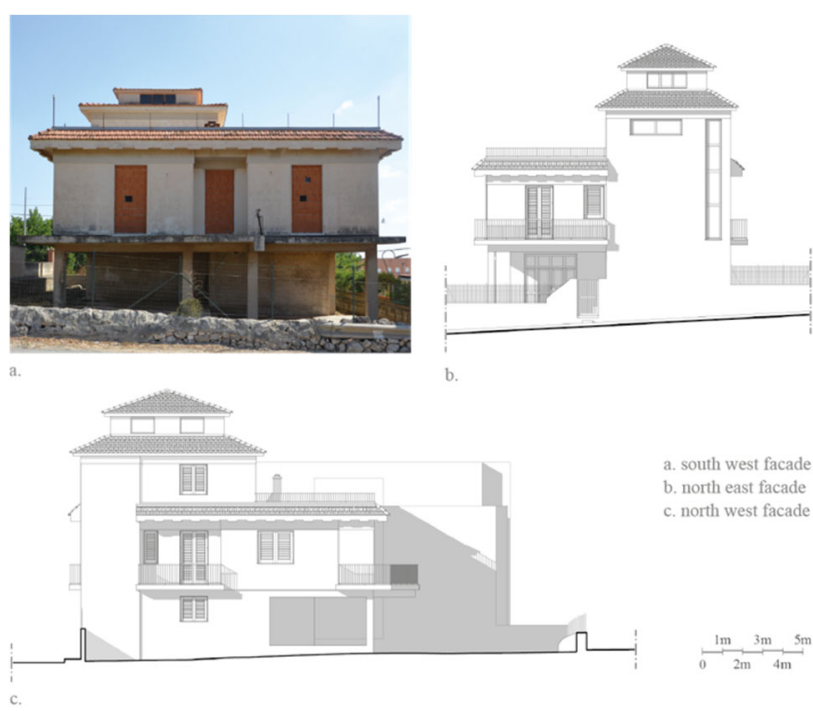

Fig. 2. Morphological features of the elevations in their existing state

All the envelope structures have no thermal insulation, which results in high thermal transmittance values and low inertial capacity (Fig. 3).

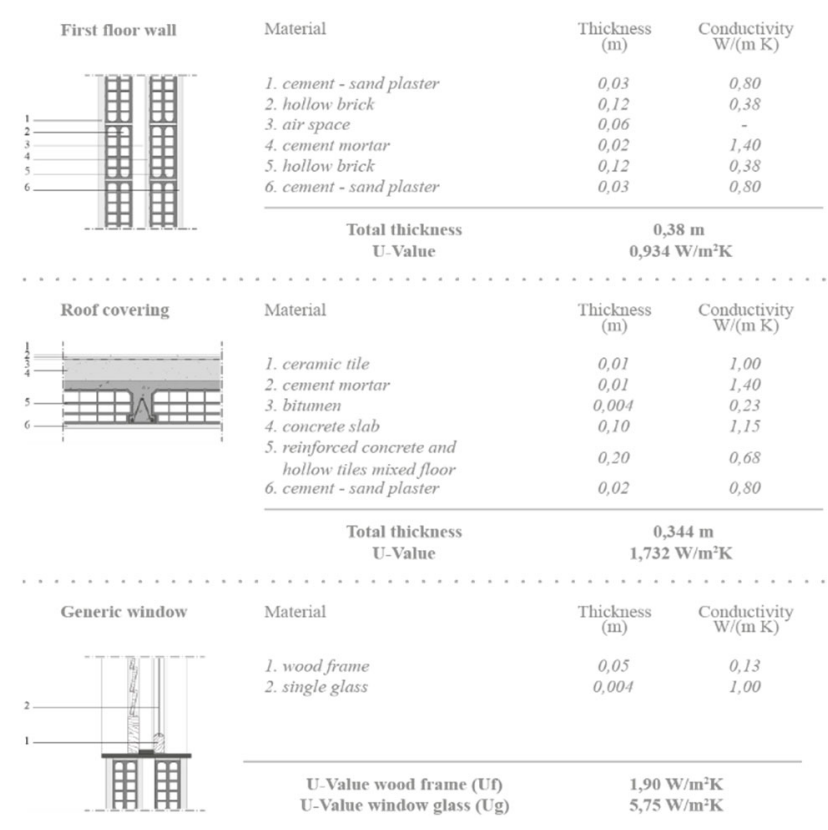

Fig. 3. Stratigraphy and transmittance values of certain envelope components in their present state 


\section{B. Solar analysis}

Using the Sun Path and Insight Solar Analysis plug-ins for Autodesk Revit software, an annual solar analysis was carried out, and in particular the two solstices - 21 December and 21 June - were taken into account, evaluating the behaviour of shadows and incident solar radiation on the various envelope surfaces (Fig. 4).

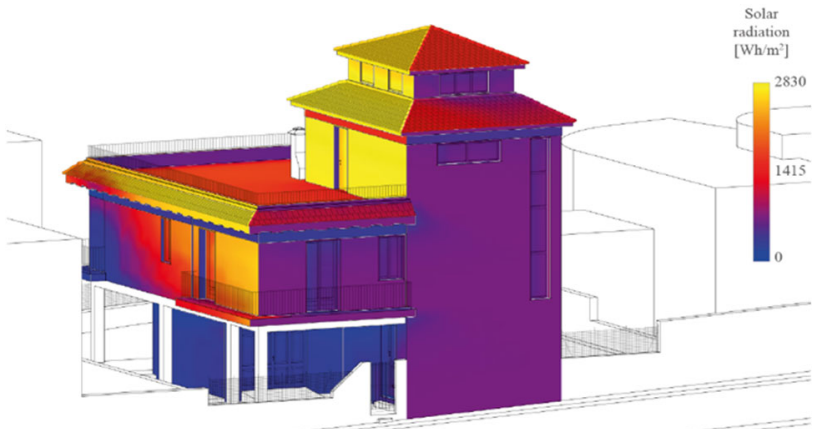

Fig. 4. Example of an analysis of incident solar radiation in the south-east and north-east fronts on 21/12/2019 from 7:00 am to $4: 45 \mathrm{pm}$

These analyses show that in winter most of the surfaces to the south-east and south-west do not receive good sunlight, either because of the adjacent building to the south-east or because of the architectural configuration of the building. The sunniest surfaces are the horizontal roof surfaces, the vertical surfaces of the first and second floors to the south-west and the second floor to the south-east, which have the highest cumulative incident solar radiation values: 1500 Watt hours $/ \mathrm{m}^{2}$ for the horizontal roof surfaces, 1950 Watt hours $/ \mathrm{m}^{2}$ for the vertical surfaces of the first and second floors to the south-west, 2830 Watt hours $/ \mathrm{m}^{2}$ for the vertical surfaces of the second floor to the south-east. In summer, however, the building only benefits from its own shadows. While the portico on the ground floor is functional because it provides shade throughout the day on the various fronts, the canopies on the upper floors are not as effective on the south-west front. This is where some of the highest values of cumulative solar radiation are recorded, at around $3500 \mathrm{Watt}$ hours $/ \mathrm{m}^{2}$. On the roof, on the other hand, values of 7040 Watt hours $/ \mathrm{m}^{2}$ are recorded.

\section{Natural lighting analysis}

Using the Diva plugin for Rhinoceros software, the levels of natural lighting in the main rooms of the building were assessed using dynamic metrics such as Daylight Autonomy (DA) and Useful Daylight Illuminance (UDI), both based on a specific annual occupational schedule of 3650 hours (Fig. 5). The analysis shows acceptable natural lighting conditions only on the first floor (range - DA: $39.08 \%$ to $79.64 \%$, UDI: $72.48 \%$ to $82.91 \%$ ), while on the other floors the values are below those considered optimal (range - ground floor DA: 1.44\%, UDI: $22.87 \%$; second floor DA: $18.58 \%$, UDI: $60.43 \%$ ).
$\mathrm{DA}_{300 \mathrm{lux}}$

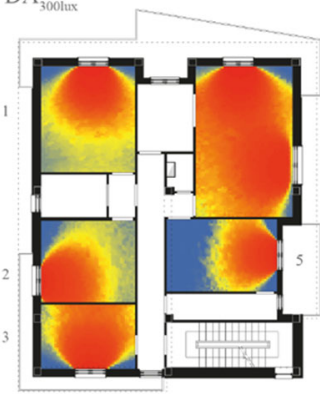

$\mathrm{UDI}_{100}$

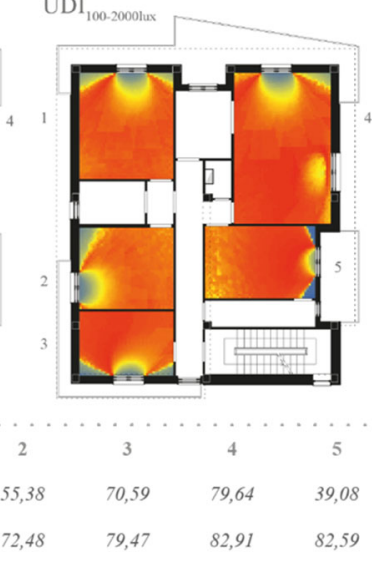

Fig. 5. Example of annual analysis of DA and UDI values of the first floor

\section{Natural ventilation analysis}

Using Autodesk CFD software, fluid dynamic analyses are carried out to evaluate the interaction between the prevailing winds and the surfaces of the building envelope (Fig. 6). In winter (December-February), the prevailing winds blow from the east at a maximum speed of approximately $30 \mathrm{~km} / \mathrm{h}$, while in summer (June-August), the prevailing winds blow from the west at a maximum speed of approximately $45 \mathrm{~km} / \mathrm{h}$.

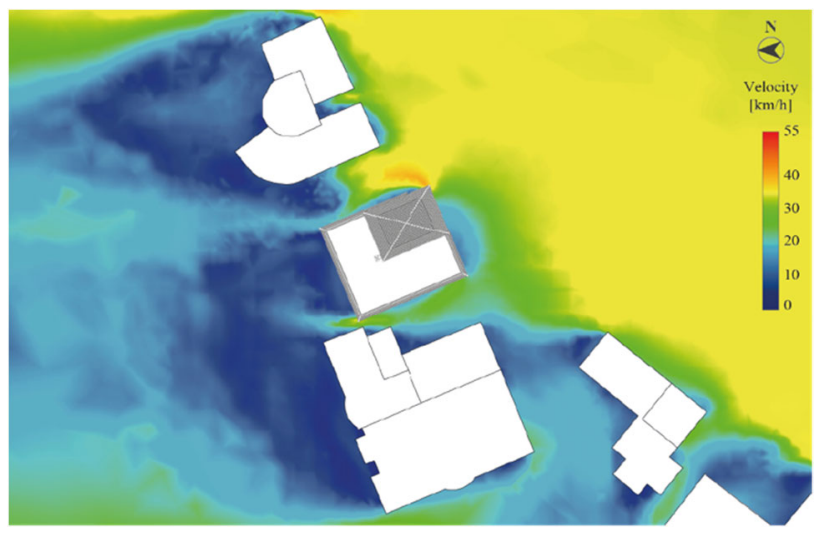

Fig. 6. Example of fluid dynamics analysis for the period December-February

The air flows generated by the prevailing winds during these periods affect the south-east and north-west surfaces with an angle of incidence of $22.5^{\circ}$, and the north-east and south-west surfaces with an angle of incidence of $67.5^{\circ}$.

\section{E. Comfort and heat balance}

Using the Design Builder software, in consideration of the climatic file of the nearest metereological station, Cozzo Spadaro (Portopalo di Capo Passero - SR), annual dynamic energy analyses were carried out to evaluate the thermophysical behaviour of the building in the most critical days of the winter period (from 2 to 6 January) and of the summer period (from 6 to 10 August). In particular, for these periods, the comfort indices (Predicted Mean 
Vote - PMV, Predicted Percentage of Dissatisfied - PPD, Operating Temperature - $\mathrm{T}_{\mathrm{OP}}$ ) [4] were evaluated in the absence of active air conditioning systems and taking into account shading systems (shutters) and night ventilation. From the analysis of the results in the winter period, the $\mathrm{T}_{\text {OP }}$ presents a minimum value of $9{ }^{\circ} \mathrm{C}$ and a maximum value of no more than $12^{\circ} \mathrm{C}$ and average PMV values of 2.6, which denote a feeling of "very cold". In the summer period, the TOP has a minimum value of $26.9^{\circ} \mathrm{C}$ and a maximum of $31.2^{\circ} \mathrm{C}$, with maximum PMV values of 2.1 on the hottest days, indicating a feeling of "hot". These results depend on the poor thermophysical characteristics of the building envelope and its morphology, as demonstrated by the results of the building's winter and summer energy needs (Fig. 7) [5]. In fact, the useful energy factor for heating the envelope $\left(\mathrm{EP}_{\mathrm{H}, \mathrm{INV}}\right)$ is 74.84 $\mathrm{kWh} / \mathrm{m}^{2} \mathrm{a}$ while the useful energy factor for cooling the envelope $\left(\mathrm{EP}_{\mathrm{C}, \mathrm{INV}}\right)$ is $20.10 \mathrm{kWh} / \mathrm{m}^{2} \mathrm{a}$. In both cases the most significant contribution to the definition of this requirement is due to the thermal energy lost through transmission through the envelope structures $\left(\mathrm{Q}_{\mathrm{TR}}\right)$.
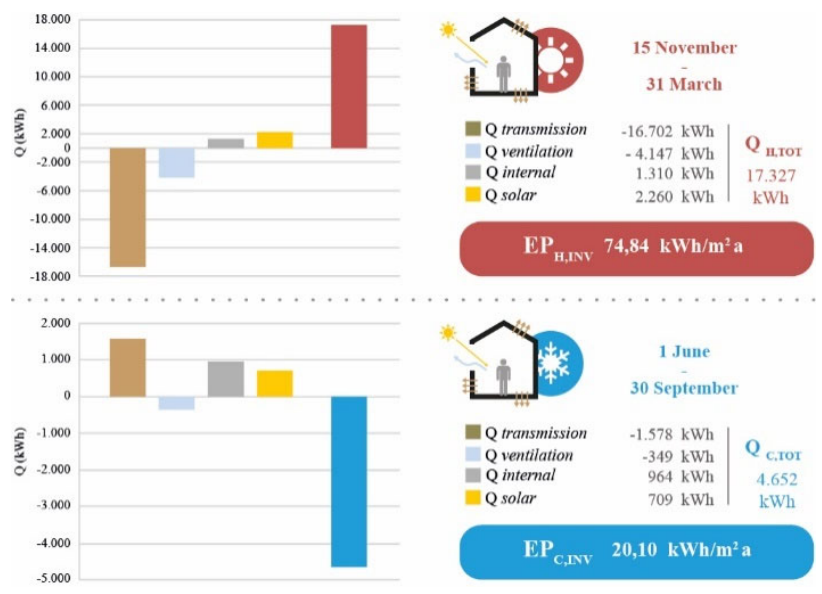

Fig. 7. Heat balance of the building in the winter period (15 November - $31 \mathrm{March}$ ) and in the summer period (1 June - 30 September)

\section{Design strategies and solutions}

The aim of the proposed design solutions is the total reconfiguration of the building through the application of strategies typical of bioclimatic, green building and ecological architecture aimed at respecting and safeguarding the relationship between man, building and environment [6].

\section{F. The Project}

The design strategies have led to a project that seeks to reinterpret the characteristics of Mediterranean architecture through bioclimatic evaluations that redefine the external volumes, the logic of the holes and the internal spatial articulation, generating a new architectural form [7]. On the outside, the subtraction of all the elements characterising the irregularity of the current configuration produces a building with a simple, linear and compact volume (Fig. 8).

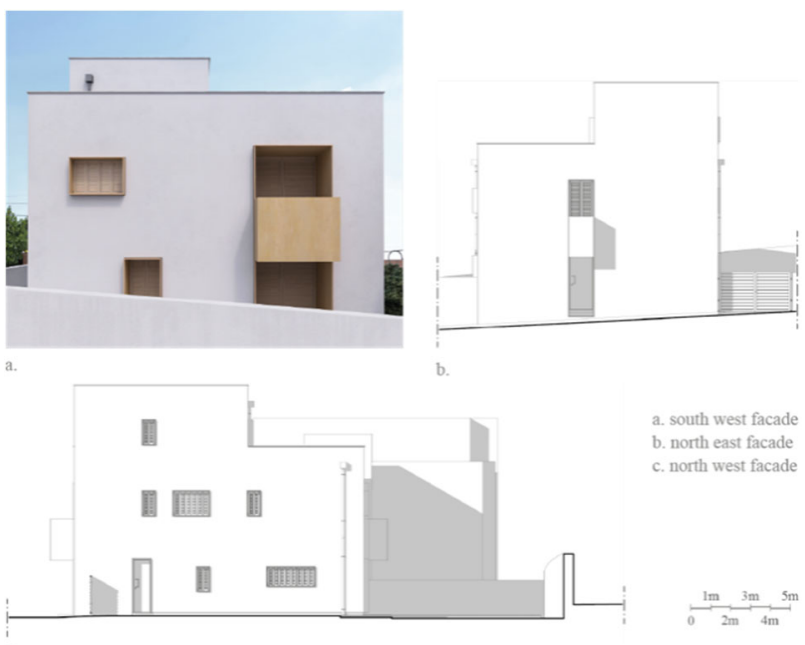

Fig. 8. Morphological characteristics of the elevations in the design state

From a construction point of view, the objective was to obtain envelope components with high resistance and thermal inertia. In this way the well-being of the occupants is granted through the use, however, of eco-friendly materials with low environmental impact in accordance with the principles of green building and ecological architecture. To this end, the main interventions are:

- the replacement of the curtain walls with a new "wall package" made of heat-insulating blocks in biocomposite of hemp and lime, with natural lime finishes;

- the thermal insulation of the floor against the ground and the roof with a heat-insulating screed, again in biocomposite of hemp and lime;

- $\quad$ the replacement of the transparent closures with new windows and doors characterised by a wooden frame with thermal break and double glazing (Fig. 9).

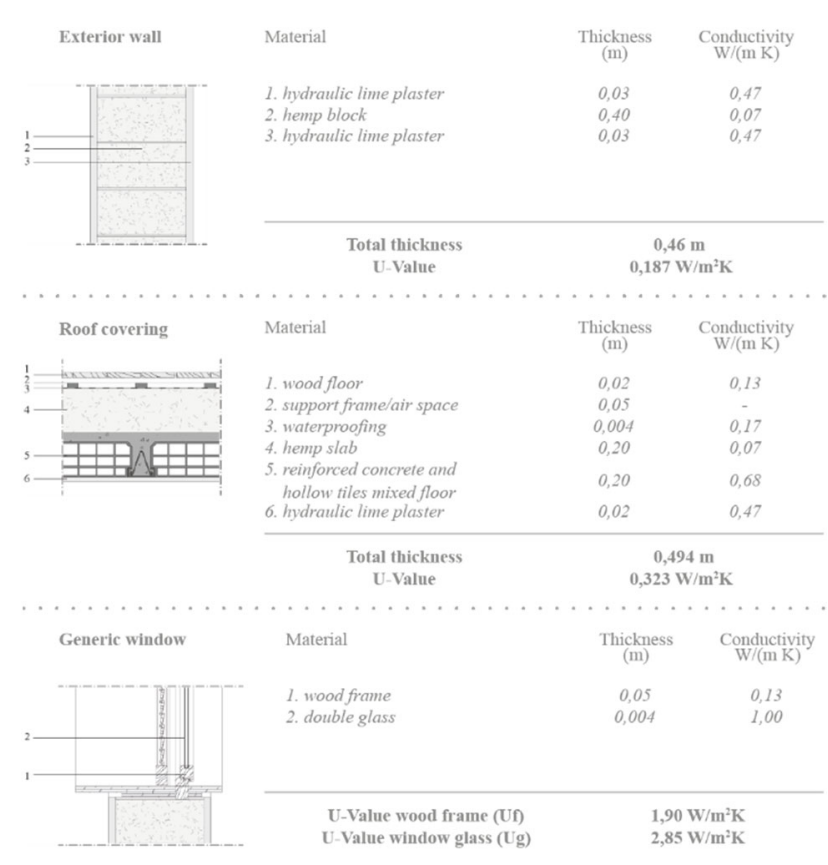

Fig. 9. Stratigraphy and transmittance values of some envelope components in the design state 
In addition, all the openings are fitted with fixed (loggias and projecting rooflights) and movable (shutters) screens to prevent overheating. Depending on their size, the windows and shutters are opened in different ways: casement, folding or sliding. Wooden slats protrude externally in a variable manner depending on the orientation of the sun path and the shutters, when open, are always incorporated within the overhang so as not to alter the perception of the architectural composition and to be protected from the weather (Fig. 10).

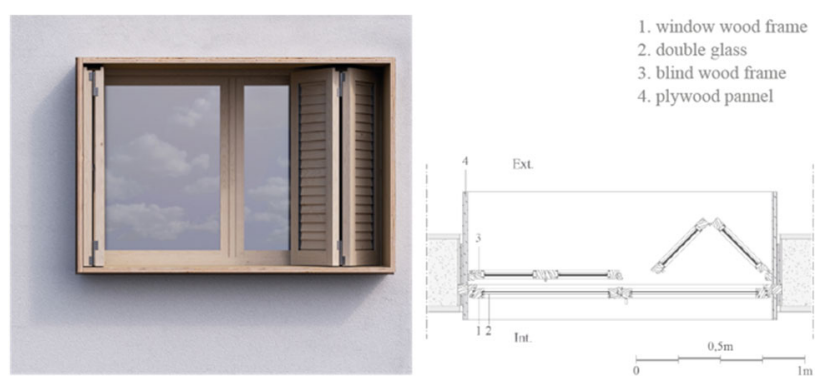

Fig. 10. South-west elevation window detail

\section{Results}

In general, the orientation and sizing of the new openings and the choice of light colours for the internal finishes, guarantee, unlike the pre-intervention condition, good levels of natural lighting for all floors of the building as found by the analysis of the Daylight Autonomy and the Useful Daylight Illuminance (range of values - ground floor DA: $56.91 \%$, UDI: $74.90 \%$; first floor DA: from $49.67 \%$ to $61.32 \%$, UDI: from $74.10 \%$ to $85.70 \%$; second floor DA: $64.02 \%$, UDI: 70.10\%) (Fig. 11).

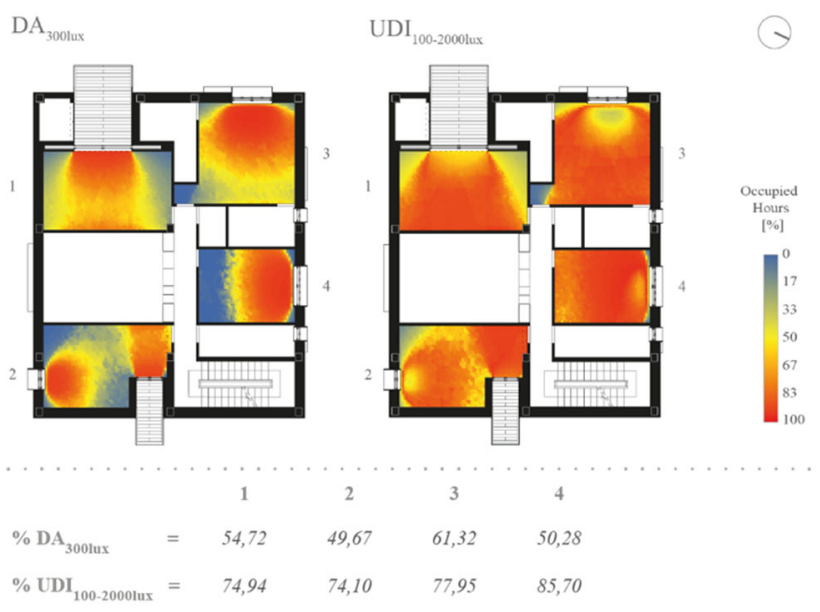

Fig. 11. Example of annual analysis of DA and UDI values of the first floor in the design state

The comfort analyses carried out in a similar way to those carried out for the pre-intervention condition and always considering the non-active air conditioning systems show how the morphological and construction solutions adopted are effective in achieving optimal comfort values. The use of biocomposite materials of hemp and lime applied to the opaque structure guarantees excellent inertial properties with phase displacement values of about 24 hours. In addition, in winter there is an increase in the average $\mathrm{T}_{\mathrm{OP}}$ of about $3.3{ }^{\circ} \mathrm{C}$. On the hottest days of summer, the maximum $\mathrm{T}_{\mathrm{OP}}$ values drop by approximately $3.5{ }^{\circ} \mathrm{C}$, reaching $27.7{ }^{\circ} \mathrm{C}$, and the minimum values by approximately $1{ }^{\circ} \mathrm{C}$, reaching $26.2{ }^{\circ} \mathrm{C}$. It should also be noted that natural ventilation at night further improves comfort with maximum $\mathrm{T}_{\mathrm{OP}}$ values of no more than $27^{\circ} \mathrm{C}$. The analysis of the air conditioning requirements (calculated for the new usable surface area of $261 \mathrm{~m}^{2}$ ) shows an improvement in the value of the useful energy for heating the building envelope $\left(\mathrm{EP}_{\mathrm{H}, \mathrm{INV}}\right)$, which is 19.98 $\mathrm{kWh} / \mathrm{m}^{2} \mathrm{a}$, about $73 \%$ lower than in the existing state. This improvement is mainly due to the reduction of the thermal energy exchanged by transmission $\left(\mathrm{Q}_{\mathrm{TR}}\right)$ and above all to the reduction of the dispersions of the perimeter walls (from 5,598 to 1,186 kWh) and of the roofs (from 3,597 to $951 \mathrm{kWh}$ ). There is also an $84 \%$ reduction in the demand for summer air conditioning with a useful energy factor for cooling the envelope $\left(\mathrm{EP}_{\mathrm{C}, \mathrm{INV}}\right)$ of $2.74 \mathrm{kWh} / \mathrm{m}^{2} \mathrm{a}$. This is due, again, to the reduction of the thermal energy exchanged by transmission $\left(\mathrm{Q}_{\mathrm{TR}}\right)$ and, in particular, to the incoming loads from walls (from 1,154 to $18 \mathrm{kWh}$ ) and roofs (from 2,805 to $279 \mathrm{kWh}$ ) (Fig. 12).

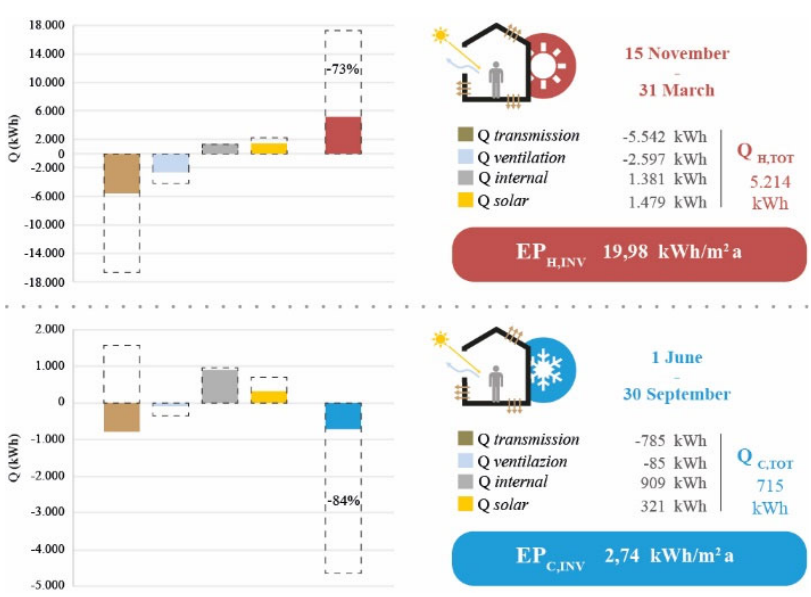

Fig. 12. Heat balance of the building in the winter period (15 November - $31 \mathrm{March}$ ) and in the summer period (1 June - 30 September) in the design state

\section{G. LCA Analysis}

In order to understand the measure of the ecological nature of the project intervention, an environmental evaluation with LCA [8] of the production phase [A1-A3] of the proposed intervention was carried out. In order to accomplish this investigation, the Environmental Product Declarations (EPD) of the materials making up the stratigraphy of the new envelope components were consulted, considering in particular, among the various impact indicators, the Primary Energy Input (PEI) and the Global Warming Potential (GWP) (Fig. 13). From the calculation of these impacts, it emerged that the production phase of the intervention is characterised by a total PEI value of $1.083 .188 \mathrm{MJ}, 52 \%$ of which comes from renewable energy sources, and by a negative GWP value of $-11.172 \mathrm{kgCO}_{2}$ eq (Fig. 14), representing an "environmental gain" deriving above all from the use of building materials of plant origin which, in their original 
state as plants, during their growth phase, manage to absorb $\mathrm{CO}_{2}$ from the atmosphere.

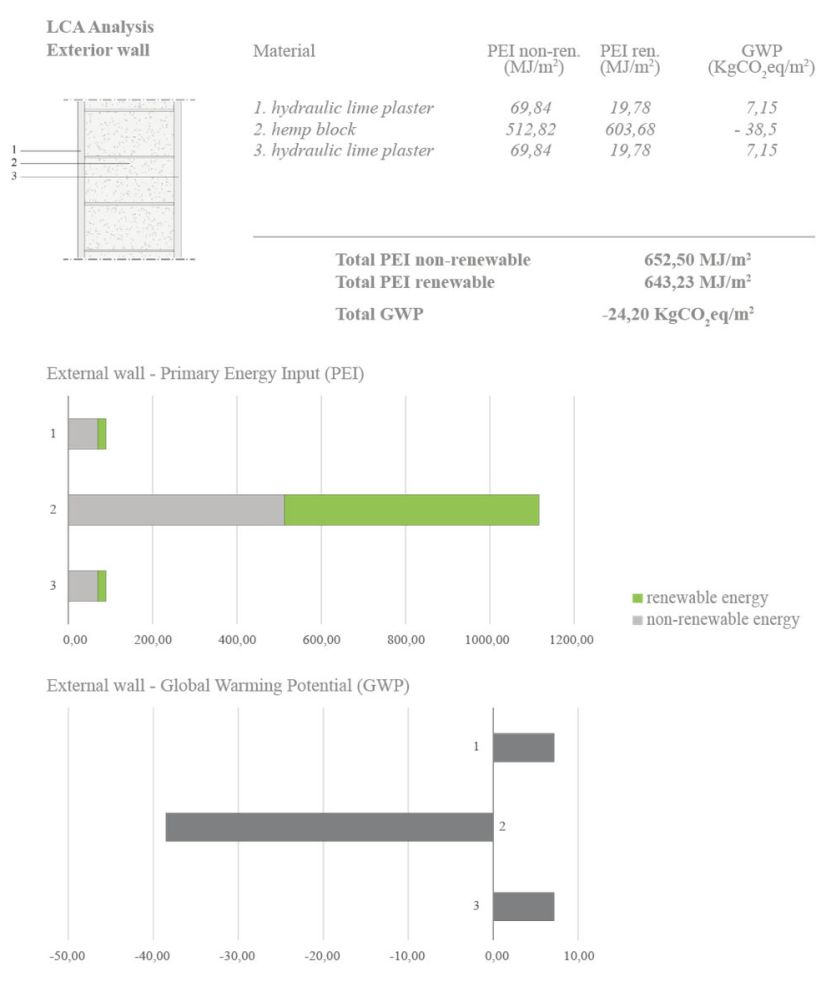

Fig. 13. Example of LCA analysis of envelope component in the design state: external wall

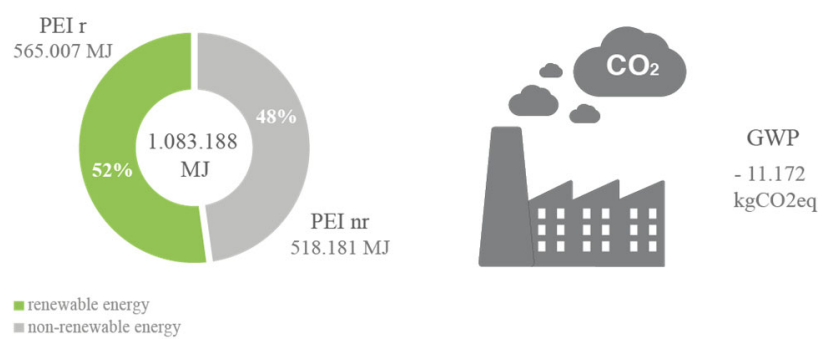

Fig. 14. Total PEI and GWP values of the production phase [A1A3] of the project intervention

The aim of this analysis was also to highlight the environmental benefits of transforming the building compared to demolishing and rebuilding it. The reuse of the existing load-bearing structure avoids the consumption of 252.089 MJ of non-renewable primary energy that would otherwise have been required, in the case of demolition and reconstruction, for the construction of a new load-bearing structure similar to the previous one, while saving $41.058 \mathrm{kgCO}_{2}$ eq.

\section{Conclusions}

This study shows how architectural design, in its ethical value as a tool for interpreting the relationship between man and resources and in its technical value as a search for solutions aimed at saving resources and achieving indoor wellbeing, can and must be the first tool for controlling the environmental sustainability requirements of buildings, including existing ones. In conclusion, there is a need to change perspective and introduce a new approach to thinking about and designing buildings, consisting of a change that is more cultural than technological. This is an articulated and complex framework of reference, but one that is essential if we are to approach design with competence, technique and cultural awareness in relation to the transformative processes affecting the environment in which we live. It is therefore necessary to follow a new path that manages to make innovative technologies and traditional knowledge coexist in a "virtuous" architecture that does not confront nature but respects its laws. Therefore, the proposed methodology of redevelopment of the case study in question, combining the theme of architectural quality with that of environmental sustainability, proves the validity of this practice.

\section{References}

[1] T. Abergel, J. Dulac, I. Hamilton, M. Jordan, A. Pradeep, P. Dean, C. Delmastro, D. Motherway, M. Slade, N. Nass, M. Otto, N. Steurer, 2019 Global Status Report for Buildings and Construction, UN Environment Programme and IEA (2019).

[2] M. Lavagna, Lyfe cycle Assessment in edilizia. Progettare e costruire in una prospettiva di sostenibilità ambientale, Hoepli, Milano (2008).

[3] M. Lavagna, E. Baleani, E. Gonzi, A. Bessi, A. Della Valle, S. Ganassali, S. Giorgi, M. Decio, M. Mazzetti, L. Fagandini, S. Marinelli, A. Meneghelli, M. Ojan, Life Cycle Assessment in edilizia, Rovereto, (2019) Green Building Council Italia (GBCI).

[4] S. Coccolo, J. Kämpf, J. L. Scartezzini, D. Pearlmutter, Outdoor human comfort and thermal stress: A comprehensive review on models and standards, Elsevier, Amsterdam (2016).

[5] F. Leone, F. C. Nigrelli, "Urban Changes to Control and Mitigate the Urban Heat Islands (UHI): Analysis in the Catania's Territory", SpringerNature (2021).

[6] M. Fernandez-Antolin, J. M. del Río, V. Costanzo, F. Nocera $\&$ R. Gonzalez-Lezcano, "Passive design strategies for residential buildings in different spanish climate zones", Sustainability (Switzerland), (2019) 11(18).

[7] F. Nocera, R. Caponetto, G. Giuffrida \& M. Detommaso, "Energetic retrofit strategies for traditional sicilian wine cellars: A case study", Energies, (2020) 13(12)

[8] M. R. Trovato, F. Nocera \& S. Giuffrida, "Life-cycle assessment and monetary measurements for the carbon footprint reduction of public buildings", Sustainability (Switzerland), (2020) 12(8) 